\title{
Structural Differences between the Lignin-Carbohydrate Complexes (LCCs) from 2- and 24-Month-Old Bamboo (Neosinocalamus affinis)
}

\author{
Pan-Pan Yue ${ }^{1}$, Ya-Jie Hu ${ }^{1}$, Gen-Que Fu ${ }^{1}$, Chang-Xia Sun ${ }^{2}$, Ming-Fei Li ${ }^{1}$, Feng Peng ${ }^{1, *}$ and \\ Run-Cang Sun ${ }^{1}$ \\ 1 Beijing Key Laboratory of Lignocellulosic Chemistry, Beijing Forestry University, Beijing 100083, China; \\ ypp1109@bjfu.edu.cn (P.-P.Y.); huyajie@bjfu.edu.cn (Y.-J.H.); fugenque@bjfu.edu.cn (G.-Q.F.); \\ limingfei@bjfu.edu.cn (M.-F.L.); rcsun3@bjfu.edu.cn (R.-C.S.) \\ 2 College of Science, Beijing Forestry University, Beijing 100083, China; sxinghan@163.com \\ * Correspondence: fengpeng@bjfu.edu.cn; Tel./Fax: +86-10-6233-7250
}

Received: 21 November 2017; Accepted: 12 December 2017; Published: 21 December 2017

\begin{abstract}
The lignin-carbohydrate complex (LCC) was isolated from milled wood lignin of 2- and 24-month-old crude bamboo (Neosinocalamus affinis) culms using acetic acid (AcOH) and then characterized. The results have shown that the LCC preparation from 2-month-old bamboo $\left(\mathrm{L}_{2}\right)$ exhibited a slightly lower molecular weight than the LCC preparation from the 24-month-old bamboo $\left(\mathrm{L}_{24}\right)$. Further studies using Fourier transform infrared spectroscopy (FT-IR) and heteronuclear single quantum coherence (2D-HSQC) NMR spectra analyses indicate that the LCC preparations included glucuronoarabinoxylan and G-S-H lignin-type with G>S > $>$ H. The content of the $S$ lignin units of LCC in the mature bamboo was always higher than in the young bamboo. Combined with sugar composition analysis, the contents of phenyl glycoside and ether linkages in the $\mathrm{L}_{24}$ preparation were higher than in the $\mathrm{L}_{2}$ preparation; however, there was a reverse relationship of ester LCC bonds in $\mathrm{L}_{2}$ and $\mathrm{L}_{24}$. Lignin-xylan was the main type of LCC linkage in bamboo LCCs. Lignin-lignin linkages in the LCC preparations included $\beta-\beta, \beta-5$ and $\beta-1$ carbon-to-carbon, as well as $\beta-O-4$ ether linkages, but $\beta-1$ linkages were not present in $\mathrm{L}_{2}$.
\end{abstract}

Keywords: 2- and 24-month-old bamboo; chemical composition; LCC preparations; lignin and lignin-carbohydrate complex linkages; 2D-HSQC NMR

\section{Introduction}

Bamboo, an abundant renewable biomass resource, consists of cellulose, hemicelluloses, and lignin, which are associated with one another through physical binding and chemical linkages to form complex structures [1,2]. Based on the current state of knowledge, cellulose is a linear homopolysaccharide, which is composed of D-glucose units linked by $\beta-(1-4)$ glycosidic bonds [3]. Hemicelluloses are polysaccharides, which include xylans, mannans, $\beta$-glucans with mixed linkages, and xyloglucans [4]. Lignin consists of phenylpropane units of the guaiacyl (G), syringyl (S), and $p$-hydroxyphenyl $(\mathrm{H})$ units, which are connected with a relatively low amount of $p$-coumarate and ferulic esters of lignin, and the inter-units of lignin are mainly linked by chemical bonds of $\beta-O-4$, $\beta-\beta, \beta-5$, and $\beta-1$ types $[5,6]$. Lignin in the $S_{2}$ layer of the secondary wall has a greater chance of having covalent or hydrogen bonds with carbohydrates [7]. In isolated samples, most lignin is attached to hemicelluloses but not to cellulose, probably because cellulose forms strings that are partly crystalline [8]. Lignin and hemicelluloses are generally considered to be linked to one another through covalent bonds, which gives them high mechanical strength and makes the plant cell walls resistant to 
biodegradation. These bonds and interactions are thought to interfere with their separation from and the degradation of the plant [9]. This may be crucial to the rigidity of lignified plant cell walls.

It is generally supposed that lignin polymers are linked covalently to carbohydrates to form lignin-carbohydrate complexes (LCCs) [8]. Covalent linkages between lignin and carbohydrates have been found in wood; however, knowledge of its types, frequencies, and quantities are still insufficient [10]. Three main types of LCC linkages in the lignocellulosic biomass include benzyl esters, benzyl ethers, and phenyl glycosides. Extensive investigations have been carried out to separate and elucidate the nature of LCC, and there have been some comprehensive evaluations of the subject [11,12]. Imamura et al. [13] reported that Japanese beech water-soluble LCC has a 7.6\% lignin content, an $80 \%$ carbohydrate content, and a 10\% uronic acid content. Karlsson and Westermark [14] used the $\mathrm{LiCl}$-dimethylacetamide cellulose solvent system to dissolve kraft pulps prepared from pine and birch and found that a considerable amount of the residual lignin was chemically linked to the high molecular weight cellulose in pine but not in birch. Yaku et al. [15] studied for the first time that acidic LCCs separated from pine Björkman LCCs form micelles. Although some research about the chemical and physical properties of LCCs has been conducted, there is little evidence about the chemical composition and structure of bamboo (Neosinocalamus affinis) LCCs. More importantly, the characteristics of LCC linkages have not yet been completely elucidated due to its structural complexity.

The isolation of LCCs is an essential step in analyzing cell-wall compounds. Therefore, to obtain dependable and representative results, the method that is used to prepare the LCCs is a critical factor. The methods used for isolating LCCs include water, organic solvent, and water-organic solvent extractions. The structures of the LCCs prepared from different isolation methods present similarities and differences $[16,17]$. In this paper, the LCC preparations were obtained by purifying milled wood lignin (MWL) from crude bamboo culms with AcOH. Azuma et al. [18] have reported on the LCC extracted from the milled wood lignin from Pinus densiflora; the main backbone structure of the carbohydrate moiety in the LCC fractions consisted of $(1 \rightarrow 4)$-linked D-mannopyranosyl residues with high branches. The investigation by Freudenberg et al. [19] has shown that the LCC bonds are divided into $\alpha$-ether, phenyl glycoside, acetal, ester bonds, and combination types for -C-O- or -C-C- of free radical linkages. There are many studies on the chemical bond linkages of LCCs; however, knowledge about LCC linkages is still uncertain.

In the bamboo cell wall, polyphenol-ferulic acid (FA) is linked by an ester bond to the hemicellulose, which is connected to the lignin with an ether bond, forming a structure with hemicellulose-ester-ferulic acid-ether-lignin linkages. The cell walls from bamboo with different ages and from different species will have different chemical compositions; this is the basis for utilizing bamboo to research diversity. At present, there is a great deal of knowledge about wood; however, little information is available on the composition of LCC in bamboo. Basically, studies on LCC formation and structure during the growth stages of bamboo is still limited. There are barely any studies on the structural characterization of LCC from Neosinocalamus affinis bamboo at different growth ages. According to our previous research [20], LCC preparations were isolated from 2-, 4-, and 6-month-old Neosinocalamus affinis bamboo to study the variation of bamboo chemical linkages during its early stages of development. The results showed that the amounts of $\beta-5$ and phenyl glycoside linkages increase with maturation of the bamboo, while the amounts of $\beta-O-4$, benzyl ether, and benzyl ester linkages first increase and then decrease with the development of the young bamboo culms [20]. Based on the previous research, the aim of this study was to explore structural differences in the lignin-carbohydrate complex (LCC) from young and mature bamboo (Neosinocalamus affinis). Thus, in this paper, LCC preparations were extracted from 2-month-old and 24-month-old Neosinocalamus affinis bamboo, which represent to some extent young and mature bamboo, respectively. The results have been compared for chemical composition, chemical structure, and chemical bond linkages. The structural characterization was determined by a variety of methods, including high-performance anion exchange chromatography (HPAEC), gel permeation chromatography (GPC), Fourier transform infrared (FT-IR), and heteronuclear single quantum coherence (HSQC) NMR. 


\section{Results and Discussion}

\subsection{Chemical Composition of the Lignin-Carbohydrate Complex (LCC) Analysis}

Table 1 summarizes the main chemical compositions of the LCC preparations. LCC fractions were subjected to carbohydrate and lignin analysis. Information relating to bamboo's LCCs is still limited since the LCCs are difficult to separate and degrade as a result of the cross-linking between the lignin and the carbohydrates. The yield of LCC preparations was relatively low. The LCC preparations from 2-month-old $\left(\mathrm{L}_{2}\right)$ and 24-month-old $\left(\mathrm{L}_{24}\right)$ bamboo were $3.9 \%$ and $1.5 \%$ relative to the oven-dry weight of the ball-milled bamboo meal; the $\mathrm{L}_{2}$ and $\mathrm{L}_{24}$ were representative in this research. The LCC yield reduction was probably because a significant amount of lignin was isolated from the secondary walls, and under the same conditions the LCC preparation from mature bamboo was not easily extracted by the neutral solvent (96\% dioxane). Classically, the chemical cross-linking between cell wall components is more robust with plant growth. The amounts of acid-soluble lignin (ASL) and acid-insoluble lignin (AIL) mostly represent the total lignin material. The acid-insoluble lignin was usually the dominant lignin component in the plant cell wall. The content of the acid-insoluble lignin in the $\mathrm{L}_{2}$ preparation was significantly lower than in the $\mathrm{L}_{24}$ preparation, while the reverse relationship was observed in the content of acid-soluble lignin. The result shows that the percentage of acid-soluble lignin of LCC in young bamboo culms was relatively higher than in the mature bamboo culms, similar to what was reported by our group [20]. This was likely caused by the release of more acid-soluble lignin from young bamboo samples extracted by the dioxane solution. This could be explained by the fact that the lignin structure in 2-month-old bamboo, which is tender and without fully formed bamboo culm, may be different to the mature bamboo. Besides, LCC preparations contained 28.0-39.4\% carbohydrates. To verify the LCC linkages in bamboo, the sugar composition of the LCC preparations and the dimethyl sulfoxide (DMSO)-soluble hemicelluloses are summarized in Tables 1 and 2. Glucose (72.1-39.8\%) and xylose (18.7-52.2\%) were the dominant monosaccharides, while only a small amount of arabinose, mannose, and galactose was detected in the LCC preparations. However, the $\mathrm{L}_{2}$ preparation showed a relatively higher amount of glucose $(72.1 \%)$, which was approximately two-fold higher than in the $\mathrm{L}_{24}$ preparation. The strong enrichment of glucose units in the LCC preparation implies that the $\mathrm{L}_{2}$ preparation probably contained more glucan-type hemicelluloses [21]. Eriksson et al. [12] reported that there was no direct evidence for covalent linkages between lignin and cellulose.

Table 1. Yield, chemical composition, and carbohydrate content of lignin-carbohydrate complex (LCC) preparations isolated from 2-month-old $\left(\mathrm{L}_{2}\right)$ and 24-month-old $\left(\mathrm{L}_{24}\right)$ bamboo (Neosinocalamus affinis).

\begin{tabular}{|c|c|c|c|c|c|c|c|c|c|}
\hline \multirow{2}{*}{ Sample } & \multirow{2}{*}{ Yield $^{a}$} & \multicolumn{3}{|c|}{ Chemical Composition ${ }^{b}$ ( $\%$ of Relative Content) } & \multicolumn{5}{|c|}{ Carbohydrate Content ${ }^{\mathrm{c}}$ (\% of Relative Molar Content) } \\
\hline & & ASL & AIL & Carb & Ara & Gal & Glc & Xyl & Man \\
\hline $\mathrm{L}_{2}$ & 3.9 & $51.9 \pm 0.1$ & $20.1 \pm 0.3$ & $28.0 \pm 0.6$ & $1.2 \pm 0.1$ & $5.0 \pm 0.0$ & $72.1 \pm 0.3$ & $18.7 \pm 0.1$ & $3.0 \pm 0.0$ \\
\hline $\mathrm{L}_{24}$ & 1.5 & $10.9 \pm 0.3$ & $49.7 \pm 0.7$ & $39.4 \pm 0.4$ & $4.2 \pm 0.1$ & $2.2 \pm 0.2$ & $39.8 \pm 0.2$ & $52.2 \pm 0.2$ & $1.6 \pm 0.1$ \\
\hline
\end{tabular}

The data in Table 2 clearly illustrates that the DMSO-soluble hemicelluloses were a mixture of many different monosaccharides. It is quite obvious that xylose was the main sugar of the 2-month-old bamboo hemicellulose $\left(\mathrm{H}_{2}\right)$ and 24-month-old bamboo hemicellulose $\left(\mathrm{H}_{24}\right)$ preparations, while trace amounts of arabinose, galactose, glucose (except for $\mathrm{H}_{2}$ ), and glucuronic acid were also identified in bamboo hemicelluloses. This demonstrates that the bamboo hemicelluloses consists mainly of glucuronoarabinoxylans; the $\alpha$-Araf and $\alpha$-D-glucopyranosyl uronic units constitute the side chain of xylan. This result was in accordance with the analysis reported by Yoshida et al. [22]. The ratios of glucuronic acid to xylose (GlcA/Xyl) and arabinose to xylose (Ara/Xyl) represent the degree of linearity or branching of the hemicelluloses; a higher degree of branching of the xylan chains leads to a higher solubility of the polysaccharides [23]. In addition, the high amounts of glucose (22.01\%) probably resulted from the $\beta$-D-glucopyranoside unit of glucan [24]. 
Table 2. Sugar composition of dimethyl sulfoxide (DMSO)-soluble hemicelluloses extracted from 2-month-old and 24-month-old bamboo (Neosinocalamus affinis) culms.

\begin{tabular}{cccccccc}
\hline \multirow{2}{*}{ Sample $^{\mathbf{a}}$} & \multicolumn{4}{c}{ Molar Composition $^{\mathbf{b}}$ (Relative $\%$, mol/mol) } & \multicolumn{2}{c}{ Molar Ratio $^{\mathbf{c}}$} \\
\cline { 2 - 8 } & Ara & Gal & Glc & Xyl & GlcA & GlcA/Xyl & Ara/Xyl \\
\hline $\mathrm{H}_{2}$ & $11.25 \pm 0.2$ & $4.60 \pm 0.1$ & $22.01 \pm 0.1$ & $58.30 \pm 0.0$ & $3.59 \pm 0.1$ & 0.06 & 0.19 \\
$\mathrm{H}_{24}$ & $6.48 \pm 0.1$ & $0.59 \pm 0.0$ & $2.87 \pm 0.2$ & $86.93 \pm 0.0$ & $3.30 \pm 0.0$ & 0.03 & 0.07 \\
\hline
\end{tabular}

${ }^{\mathrm{a}} \mathrm{H}_{2}$ and $\mathrm{H}_{24}$ represent the 2-month-old and 24-month-old bamboo hemicelluloses, respectively. ${ }^{\mathrm{b}}$ Ara, arabinose; Gal, galactose; Glc, glucose; Xyl, xylose; GlcA, glucuronic acid. ' $\mathrm{C}$ Ara/Xyl, molar ratio of arabinose to xylose; $\mathrm{GlcA} / \mathrm{Xyl}$, molar ratio of glucuronic acid to xylose.

\subsection{Fourier Transform Infrared (FT-IR) Spectra Analysis}

FT-IR spectra of $\mathrm{L}_{2}$ and $\mathrm{L}_{24}$ preparations are shown in Figure 1, and the main assignments of FT-IR signals are summarized in Table 3 . The peak at $3399 \mathrm{~cm}^{-1}$ originated from the O-H stretching vibration in the aliphatic and aromatic OH groups, and the absorption bands in 2920 and $2851 \mathrm{~cm}^{-1}$ are due to $\mathrm{C}-\mathrm{H}\left(\mathrm{CH}_{2}\right.$ and $\left.\mathrm{CH}_{3}\right)$ stretching vibrations. The absorptions at 1657 and $1719 \mathrm{~cm}^{-1}$ are attributed to carbonyl groups, but a peak is not observed at about $2730 \mathrm{~cm}^{-1}$, implying it is a ketone group rather than an aldehyde group. Signals ranging from $1500-1600 \mathrm{~cm}^{-1}$ are assigned to aromatic skeletal ring vibration in lignin. The peaks at 1514 and $1455 \mathrm{~cm}^{-1}$ are not to be overlapped with the bands of carbohydrates, and they represent the absorption of lignin to an extent. The peaks at $1262 \mathrm{~cm}^{-1}$, $1329 \mathrm{~cm}^{-1}$, and $1167 \mathrm{~cm}^{-1}$ seem to be due to guaiacyl-, syringyl-, and $p$-hydroxyphenyl units of lignin moieties, respectively [25]. From the intensity of the absorbance at $1329 \mathrm{~cm}^{-1}, \mathrm{~L}_{24}$ has a relatively stronger absorption than $\mathrm{L}_{2}$, which indicates that there was almost no syringyl in the 2-month-old bamboo LCC preparation and that the amounts of syringyl types increase with the increasing maturity of the bamboo. The $\mathrm{C}-\mathrm{O}, \mathrm{C}-\mathrm{C}$, and $\mathrm{C}=\mathrm{O}$ stretching vibrational mode of the aromatic skeletal ring of the guaiacyl type is recognized by the presence of a signal at $1235 \mathrm{~cm}^{-1}$. In addition, the intense signal at $834 \mathrm{~cm}^{-1}$ is assigned to the aromatic $\mathrm{C}-\mathrm{H}$ out-of-plane vibrations in the $\mathrm{H}$ unit and $\mathrm{C}-\mathrm{H}$ out-of-plane vibrations in the 2,5 , and 6 positions in the $G$ units, respectively [26,27].

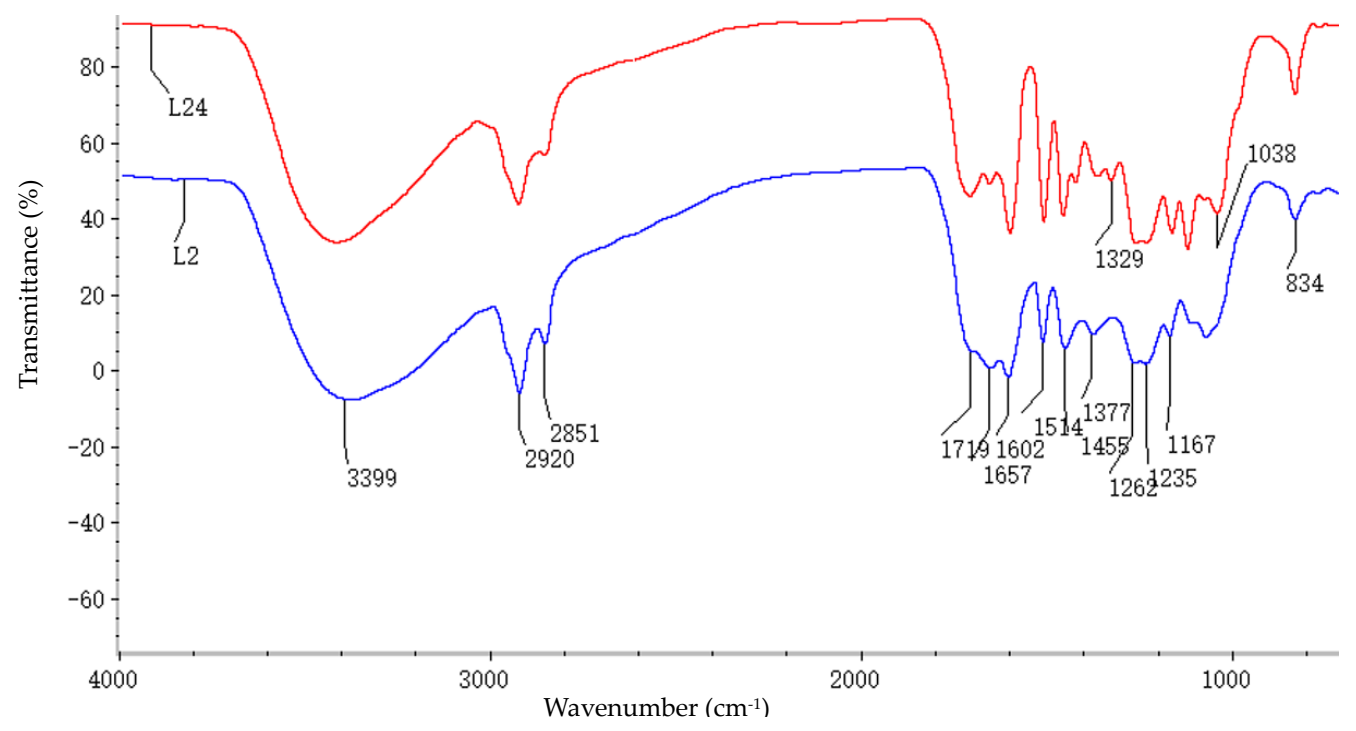

Figure 1. FT-IR of the lignin-carbohydrate complex (LCC) preparations $\left(\mathrm{L}_{2}\right.$ and $\left.\mathrm{L}_{24}\right)$. 
Table 3. Assignments of the FT-IR spectra of the LCC preparations.

\begin{tabular}{cl}
\hline Wave Numbers $\mathbf{( c m}^{\mathbf{- 1}} \mathbf{)}$ & \multicolumn{1}{c}{ Assignments } \\
\hline 3399 & O-H stretch \\
2920 and 2851 & C-H stretch in methyl and methylene groups \\
1719 & C=O stretch (unconjugated ketones, carbonyl and in ester groups in carbohydrate) \\
1657 & Conjugated C=O stretch (lignin) \\
1602 & Aromatic skeletal vibrations (lignin) \\
1514 & Aromatic skeletal vibrations (lignin) \\
1455 & Aromatic skeletal vibrations combined with C-H in-plane deform (lignin and methylene \\
1377 & groups in polysaccharide) \\
1329 & COO-asymmetric and symmetrical vibrations in carboxylate groups \\
1262 & Syringyl units \\
1235 & Guaiacyl units \\
1167 & C-C, C-O, and C=O stretch of G ring \\
1038 & Typical for HGS lignins; C=O in ester groups (conjugated) \\
834 & Aromatic C-H in-plane deformation, G > S; plus C-O deform, in primary alcohols; plus \\
& C=O stretch (unconjugated) \\
& C-H out-of-plane in positions 2, 5, and 6 of G units \\
\hline
\end{tabular}

\subsection{HSQC NMR Spectra Analysis}

The methods of wet chemistry techniques and model experiments are useful for acquiring information, while direct observation of LCC structure with spectroscopic techniques is also of primary importance [28]. NMR spectroscopy is extremely useful in ascertaining the main linkages of lignin-carbohydrate. The compositions of lignin and carbohydrates are quite complex, and thus it is difficult to distinguish the linkages of lignin and carbohydrate by general ${ }^{13} \mathrm{C}-\mathrm{NMR}$. However, 2D-HSQC can distinguish the overlapping signals presented in the ${ }^{1} \mathrm{H}$ and ${ }^{13} \mathrm{C}$ spectra, and the signal assignment is also better than in the case of 1D NMR; thus, it provides crucial structural information of the sample [29]. Classically, the 2D-HSQC spectra of lignin samples can be divided into three regions of ${ }^{13} \mathrm{C}-{ }^{1} \mathrm{H}$ correlations corresponding to the aliphatic $\left(\delta_{\mathrm{C}} / \delta_{\mathrm{H}} 10-40 / 0.5-2.5\right)$, side chain $\left(\delta_{\mathrm{C}} / \delta_{\mathrm{H}} 50-95 / 2.5-6.0\right)$, and aromatic $\left(\delta_{\mathrm{C}} / \delta_{\mathrm{H}} 95-150 / 5.5-8.0\right)$ regions [30]. In this study, the $\mathrm{L}_{2}$ and $\mathrm{L}_{24}$ preparations extracted from 2-month-old and 24-month-old bamboo (Neosinocalamus affinis) were subjected to 2D-HSQC spectra analysis to obtain detailed information (Figure 2). The assignments of the main cross-signals in the HSQC spectra are presented in Table 4, and the corresponding LCC linkages and lignin substructures are listed in Figure 3.

\subsubsection{Lignin Side Chain and Aromatic Regions}

The major inter-unit linkages within the lignin monomer ( $G, S$, and $H$ units) are $\beta-\beta, \beta-5$, and $\beta-1$ carbon-to-carbon as well as $\beta-O-4$ ether substructures. The side chain region $\left(\delta_{\mathrm{C}} / \delta_{\mathrm{H}} 50-95 / 2.5-6.0\right)$ from the 2D-HSQC spectra shows crucial information for the inter-unit linkages in lignin (Figure 2 and Table 4). The bamboo LCC preparation had structural complexity and the lignin linkages seem to be useful for acquiring information about the structure of LCCs. The $\beta-O-4$ linkages are the main inter-unit linkages in lignin [31]. The $\beta-O-4$ aryl ether linkages of $\mathrm{L}_{2}$ and $\mathrm{L}_{24}$ are presented at about $\delta_{\mathrm{C}} / \delta_{\mathrm{H}} 71.29 / 4.88$ and $60.73 / 3.39 \mathrm{ppm}$, which correspond to resonances of $\mathrm{C}-\alpha$ and $\mathrm{C}-\gamma$ positions of $\beta-O-4$ linkages, respectively. The $\mathrm{C}_{\beta}-\mathrm{H}_{\beta}$ correlation corresponding to the erythro forms of the $\mathrm{S}$ type $\beta-O-4$ substructures is presented at $\delta_{C} / \delta_{\mathrm{H}} 83.56 / 4.24 \mathrm{ppm}$ [32]. However, this signal disappeared in the side chain region of $\mathrm{L}_{2}$. In addition, the intense signals show the presence of $\beta-O-4$ in $\mathrm{L}_{24}$, while the corresponding cross-signals of $\mathrm{L}_{2}$ show relatively low intensities. The carbon-carbon linkages in the lignin structural units make it undegradable, and in the process of hydrogenated decomposition and alcoholysis lignin was not decomposed into a single unit due to the presence of carbon-carbon linkages. In addition, the common carbon-carbon linkages, such as the signals for $\beta-\beta$ resinol substructures $\left(\mathrm{C}_{\beta}-\mathrm{H}_{\beta}\right.$ in $\beta-\beta$ units, $53.57 / 3.39 \mathrm{ppm} ; \mathrm{C}_{\gamma}-\mathrm{H}_{\gamma}$ in $\beta-\beta$ units, 70.26/3.96 ppm) and phenylcoumaran substructures $(\beta-5)$, are observed in lower amounts in the preparations, and the signals for $\mathrm{C}_{\beta}-\mathrm{H}_{\beta}$ and $\mathrm{C}_{\gamma}-\mathrm{H}_{\gamma}$ correlations in $\beta-5$ units are observed at $\delta_{\mathrm{C}} / \delta_{\mathrm{H}} 53.57 / 3.39$ and $62.92 / 3.96$, respectively [32]. 
The $\mathrm{C}_{\alpha}-\mathrm{H}_{\alpha}$ correlation corresponding to the $\beta-1$ substructures in $\mathrm{L}_{24}$ is presented at $\delta_{\mathrm{C}} / \delta_{\mathrm{H}} 82.39 / 5.08$. Small signals corresponding to $\beta-1$ are observed in the side chain region of $\mathrm{L}_{24}$ and disappeared in the side chain region of $\mathrm{L}_{2}$. All of these results imply that the amount of lignin structures in the $\mathrm{L}_{2}$ preparation was less than in the $\mathrm{L}_{24}$ preparation.
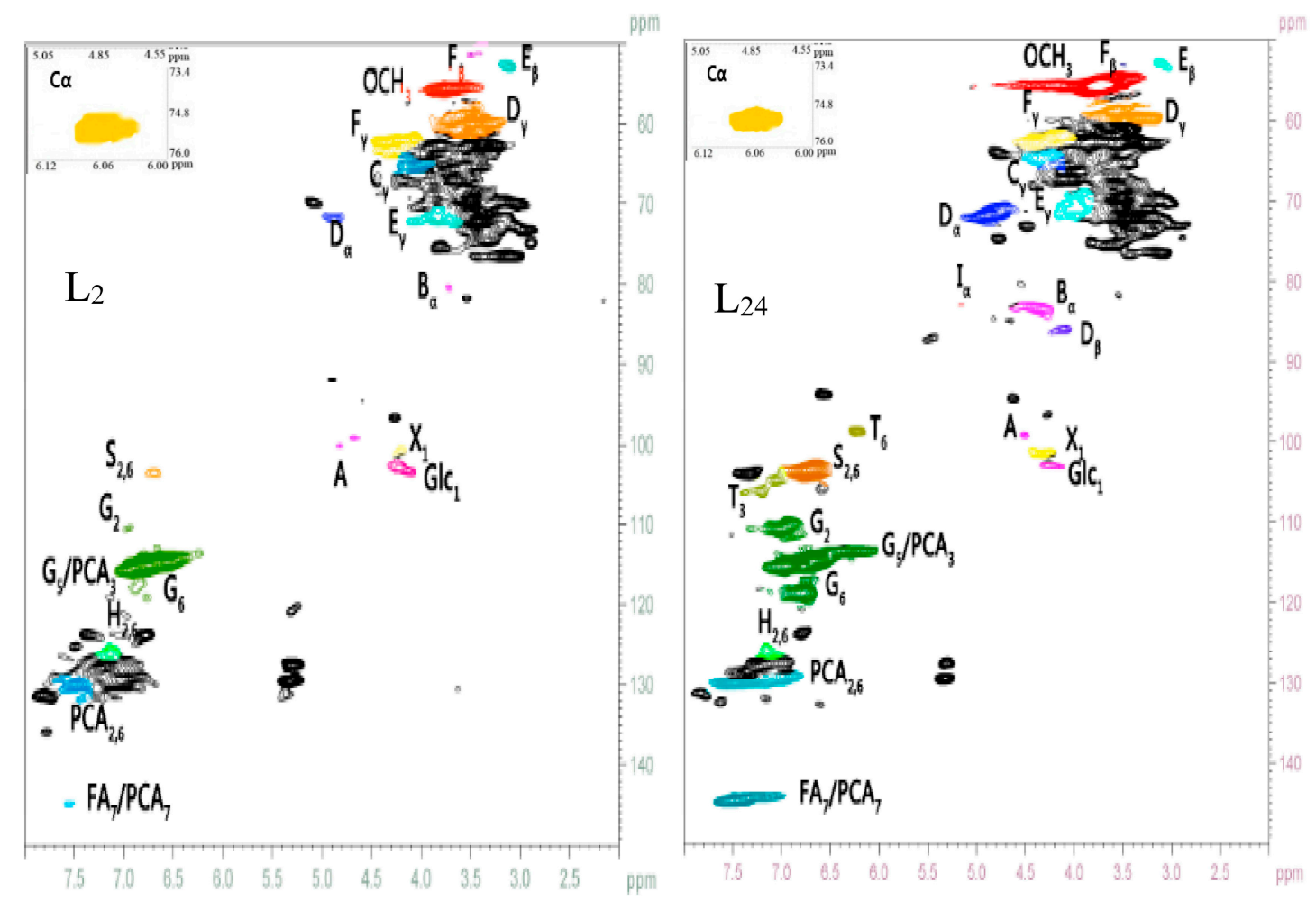

Figure 2. Main classical structures of LCC preparations identified by 2D-HSQC spectra: (A) phenyl glycoside; (B) benzyl ether; (C) ester ( $C_{\alpha}, \alpha$-ester; $C_{\gamma}, \gamma$-ester); (D) $\beta$-O-4 substructure; (E) $\beta$ - $\beta$ resinol substructure; (F) $\beta-5$ phenylcoumaran substructure; (I) $\beta-1$ spirodienone substructure; $(\mathrm{G})$ guaiacyl unit; (H) p-hydroxyphenyl unit; (S) syringyl unit; (T) tricin; (PCA) $p$-coumarate; (FA) ferulic acid unit; (Glc) $\beta$-D-glucopyranoside unit (X) $\beta$-D-xylopyranoside unit. Different colors represent different structure units.

In the aromatic regions, cross-signals are observed from the aromatic phenyl rings of guaiacyl $(\mathrm{G}), p$-hydroxyphenyl $(\mathrm{H})$, and syringyl $(\mathrm{S})$. The cross-signals at $\delta_{\mathrm{C}} / \delta_{\mathrm{H}} 115.89 / 6.76,119.34 / 6.76$, and 111.82/6.97 are attributed to $\mathrm{C}_{5}-\mathrm{H}_{5}, \mathrm{C}_{6}-\mathrm{H}_{6}$, and $\mathrm{C}_{2}-\mathrm{H}_{2}$ of $\mathrm{G}$ units, respectively. The $\mathrm{S}$ lignin units show the main cross peaks $\mathrm{C}_{2,6}-\mathrm{H}_{2,6}$ at $\delta_{\mathrm{C}} / \delta_{\mathrm{H}} 104.74 / 6.67$; however, the signal strength in $\mathrm{L}_{2}$ was weaker than in $\mathrm{L}_{24}$, which is in agreement with the results obtained in the FT-IR spectra analysis. In addition, the $\mathrm{S} / \mathrm{G}$ ratios are estimated to be 0.18 and 0.89 for $\mathrm{L}_{2}$ and $\mathrm{L}_{24}$ preparations, respectively (Table 4), which indicate that the $S$ lignin units in mature bamboo are always higher than in young bamboo. This result is in good agreement with the research reported by Zhang et al. [20]. An important feature of lignin in all plant cell walls is that the $\mathrm{S} / \mathrm{G}$ ratio can reflect, to a certain degree, the capacity to remove lignin. The $\mathrm{C}_{2,6}-\mathrm{H}_{2,6}$ correlations of the $\mathrm{H}$ units are observed as a weaker signal at $\delta_{C} / \delta_{H} 128.22 / 7.19$, indicating that there were small amounts of $\mathrm{H}$ lignin units. This result is in accordance with the studies of Bai et al. [26] and Kang et al. [27]. Moreover, $p$-coumaric acid (PCA) and ferulic acid (FA) are observed in the 2D-HSQC spectra of the $\mathrm{L}_{2}$ and $\mathrm{L}_{24}$ preparations. The cross-peaks corresponding to $\mathrm{C}_{7}-\mathrm{H}_{7}, \mathrm{C}_{3}-\mathrm{H}_{3}$, and $\mathrm{C}_{2,6}-\mathrm{H}_{2,6}, \delta_{\mathrm{C}} / \delta_{\mathrm{H}}$ at $144.76 / 7.43$ (the signals of FA and PCA were overlapped), 115.69/6.76, and 130.11/7.43, respectively, are shown in Figure 2. 
<smiles></smiles>

A

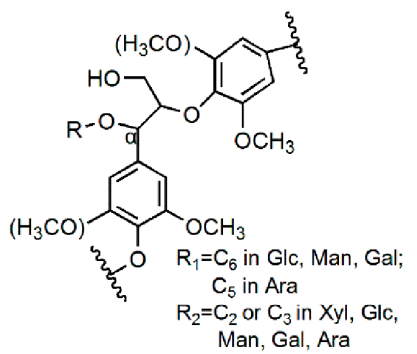

B

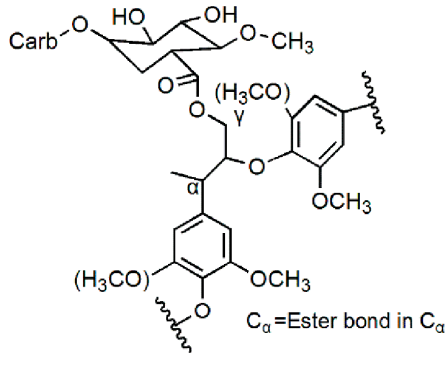

$\mathrm{C}_{\mathrm{v}}$

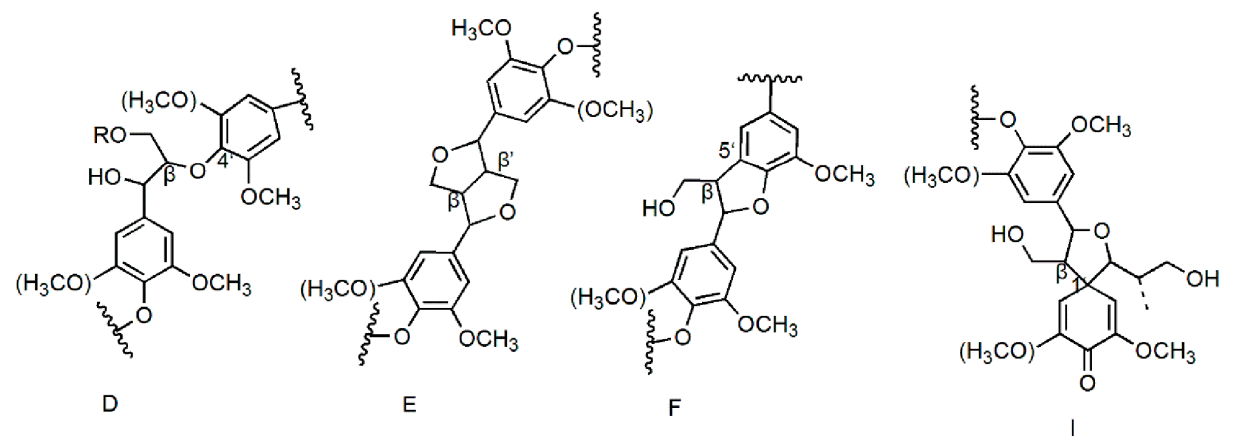<smiles>CCOc1ccc(C(C)C)cc1OCC</smiles><smiles>COc1cc(C(C)C)cc(OC)c1OC</smiles>

$\mathrm{s}$

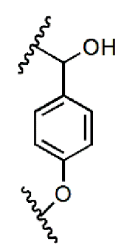

$\mathrm{H}$

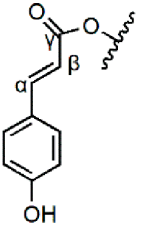

PCA<smiles>CCOC(=O)C=Cc1ccc(OCC)c(OC)c1</smiles>

FA

Figure 3. Main structures present in the LCC preparations: (A) phenyl glycoside; (B) benzyl ether; (C) ester ( $C_{\alpha}, \alpha$-ester; $C_{\gamma}, \gamma$-ester); (D) $\beta$-O-4 substructure; (E) $\beta-\beta$ resinol substructure; (F) $\beta-5$ phenylcoumaran substructure; (I) $\beta-1$ spirodienone substructure; $(G)$ guaiacyl unit; (S) syringyl unit; (PCA) $p$-coumarate; (H) $p$-hydroxyphenyl unit; (FA) ferulate unit.

Table 4. Assignments of primary lignin and carbohydrate ${ }^{13} \mathrm{C}-{ }^{1} \mathrm{H}$ cross-signals in the HSQC spectra of the LCC preparations from bamboo (Neosinocalamus affinis).

\begin{tabular}{|c|c|c|}
\hline Label & $\delta_{\mathrm{C}} / \delta_{\mathrm{H}}(\mathrm{ppm})$ & Assignments \\
\hline$-\mathrm{OCH}_{3}$ & $56.09 / 3.72$ & $\mathrm{C}-\mathrm{H}$ in methoxyls \\
\hline $\mathrm{S}_{2,6}$ & $104.74 / 6.67$ & $\mathrm{C}_{2,6}-\mathrm{H}_{2,6}$ in syringyl units $(\mathrm{S})$ \\
\hline $\mathrm{G}_{2}$ & $111.82 / 6.97$ & $\mathrm{C}_{2}-\mathrm{H}_{2}$ in guaiacyl units $(\mathrm{G})$ \\
\hline $\mathrm{G}_{5}$ & $115.89 / 6.76$ & $\mathrm{C}_{5}-\mathrm{H}_{5}$ in guaiacyl units $(\mathrm{G})$ \\
\hline $\mathrm{G}_{6}$ & $119.34 / 6.76$ & $\mathrm{C}_{6}-\mathrm{H}_{6}$ in guaiacyl units $(\mathrm{G})$ \\
\hline $\mathrm{H}_{2,6}$ & $128.22 / 7.19$ & $\mathrm{C}_{2,6}-\mathrm{H}_{2,6}$ in $p$-hydroxyphenyl units $(\mathrm{H})$ \\
\hline $\mathrm{D}_{\alpha}$ & $71.29 / 4.88$ & $\mathrm{C}_{\alpha}-\mathrm{H}_{\alpha}$ in $\beta-\mathrm{O}-4$ structures linked to a $\mathrm{S}$ unit (D) \\
\hline$D_{\beta}$ & $83.56 / 4.24$ & $\mathrm{C}_{\beta}-\mathrm{H}_{\beta}$ in $\beta-\mathrm{O}-4$ structures linked to $\mathrm{G} / \mathrm{H}$ units (D) \\
\hline $\mathrm{D}_{\gamma}$ & $60.73 / 3.39$ & $\mathrm{C}_{\gamma}-\mathrm{H}_{\gamma}$ in $\beta-\mathrm{O}-4$ structures (D) \\
\hline $\mathrm{E}_{\beta}$ & $52.97 / 3.09$ & $\mathrm{C}_{\beta}-\mathrm{H}_{\beta}$ in $\beta-\beta$ structures $(\mathrm{E})$ \\
\hline $\mathrm{E}_{\gamma}$ & $70.26 / 3.96$ & $\mathrm{C}_{\gamma}-\mathrm{H}_{\gamma}$ in $\beta-\beta$ structures $(\mathrm{E})$ \\
\hline $\mathrm{F}_{\beta}$ & $53.57 / 3.39$ & $\mathrm{C}_{\beta}-\mathrm{H}_{\beta}$ in $\beta-5$ structures $(\mathrm{F})$ \\
\hline $\mathrm{F}_{\gamma}$ & $62.92 / 3.96$ & $\mathrm{C}_{\gamma}-\mathrm{H}_{\gamma}$ in $\beta-5$ structures $(\mathrm{F})$ \\
\hline $\mathrm{I}_{\alpha}$ & $82.39 / 5.08$ & $\mathrm{C}_{\alpha}-\mathrm{H}_{\alpha}$ in $\beta-1$ structures (I) \\
\hline $\mathrm{I}_{\beta}$ & $59.62 / 2.72$ & $\mathrm{C}_{\beta}-\mathrm{H}_{\beta}$ in $\beta-1$ structures (I) \\
\hline A & $100.5 / 4.88$ & Phenyl glycoside linkages (A) \\
\hline $\mathrm{B}_{\alpha}$ & $82.5-80.0 / 4.7-4.3$ & $\mathrm{C}_{\alpha}-\mathrm{H}_{\alpha}$ in benzyl ether LCC bonds (B) \\
\hline
\end{tabular}


Table 4. Cont.

\begin{tabular}{|c|c|c|}
\hline Label & $\delta_{C} / \delta_{H}(p p m)$ & Assignments \\
\hline $\mathrm{C}_{\alpha}$ & $77.0-75.0 / 6.2-6.0$ & $\alpha$-Ester $(\mathrm{C})$ \\
\hline $\mathrm{C}_{\gamma}$ & $65-62 / 4.5-4.0$ & $\gamma$-Ester (C) \\
\hline $\mathrm{FA}_{7} / \mathrm{PCA}_{7}$ & $144.76 / 7.43$ & $\mathrm{C}_{7}-\mathrm{H}_{7}$ in $p$-coumaroylated substructures (PCA) and ferulate acid (FA) \\
\hline $\mathrm{PCA}_{3}$ & $115.69 / 6.76$ & $\mathrm{C}_{3}-\mathrm{H}_{3}$ in $p$-coumaroylated substructures (PCA) \\
\hline $\mathrm{PCA}_{2,6}$ & $130.11 / 7.43$ & $\mathrm{C}_{2,6}-\mathrm{H}_{2,6}$ in $p$-coumaroylated substructures (PCA) \\
\hline $\mathrm{X} 2$ & $72.74 / 3.09$ & $\mathrm{C}_{2}-\mathrm{H}_{2}$ in $\beta-\mathrm{D}$-xylopyranoside $(\mathrm{X})$ \\
\hline $\mathrm{X} 3$ & $73.89 / 3.37$ & $\mathrm{C}_{3}-\mathrm{H}_{3}$ in $\beta-\mathrm{D}-\mathrm{xylopyranoside}(\mathrm{X})$ \\
\hline $\mathrm{X} 4$ & $75.38 / 3.40$ & $\mathrm{C}_{4}-\mathrm{H}_{4}$ in $\beta-\mathrm{D}-\mathrm{xylopyranoside}(\mathrm{X})$ \\
\hline $\mathrm{GlcA}_{2}$ & $72.74 / 3.37$ & $\mathrm{C}_{2}-\mathrm{H}_{2}$ in glucuronic acid (GlcA) \\
\hline $\mathrm{GlcA}_{3}$ & $73.89 / 3.48$ & $\mathrm{C}_{3}-\mathrm{H}_{3}$ in glucuronic acid (GlcA) \\
\hline $\mathrm{X} 1$ & $102.21 / 4.23$ & $\mathrm{C}_{1}-\mathrm{H}_{1}$ in $\beta-\mathrm{D}-x y l o p y r a n o s i d e(\mathrm{X})$ \\
\hline $\mathrm{Glc}_{1}$ & $103.20 / 4.20$ & $\mathrm{C}_{1}-\mathrm{H}_{1}$ in $\beta$-D-glucopyranoside (Glc) \\
\hline $\mathrm{T} 3$ & $106.39 / 7.19$ & $\mathrm{C}_{3}-\mathrm{H}_{3}$ in tricin \\
\hline T6 & $99.82 / 6.22$ & $\mathrm{C}_{2,6}-\mathrm{H}_{2,6}$ in tricin \\
\hline
\end{tabular}

The spectra of the LCC preparations exhibit mainly carbohydrate cross-signals (Figure 2), including $\beta$-D-xylopyranoside units $\left(X_{1}, X_{2}, X_{3}\right.$, and $\left.X_{4}\right)$ and glucopyranoside units (Glc), which are overlapped with some other unassigned lignin moieties [33]. In addition, tricin is considered a main flavone in cereal crop plants, which is found mainly in the leaves and stems [34]. Cross-signals corresponding to $\mathrm{C}_{3}-\mathrm{H}_{3}$ at $\delta_{\mathrm{C}} / \delta_{\mathrm{H}} 106.39 / 7.19$ and $\mathrm{C}_{6}-\mathrm{H}_{6}$ at $\delta_{\mathrm{C}} / \delta_{\mathrm{H}} 99.82 / 6.22$ are shown in the $\mathrm{L}_{24}$ preparation 2D-HSQC spectra (Figure 2 and Table 4), which are attributed to tricin [26]. However, the above signals are not observed in the HSQC spectra of the $\mathrm{L}_{2}$ preparation.

\subsubsection{Major LCC Linkages}

The predominant types of LCC linkages consist of benzyl-ether, benzyl-ester, and phenyl-glycoside bonds [29,35]. Only limited research has focused on the quantitative information of these LCC linkages [28]. Some correlations in the anomeric regions may demonstrate the existence of phenyl glycoside linkages. It is noteworthy that phenyl glycoside linkages seem to be easily cleaved under mildly acidic conditions [36]. Phenyl glycoside linkages give the cross-signals of $\mathrm{CH}-1$ at $\delta_{\mathrm{C}} / \delta_{\mathrm{H}} 104-99 / 5.2-4.8$ in the 2D-HSQC spectrum; however, Figure 2 shows only one signal in the area of carbohydrates at $\delta_{\mathrm{C}} / \delta_{\mathrm{H}} 100.5 / 4.88$, which is attributed to $\mathrm{CH}-1$ included in the phenyl glycoside bonds based on data from corresponding model compounds [37]. This indicates that phenyl glycoside linkages are the bonds between carbohydrates (xylan and glucan) and lignin. Recently, Yuan et al. [33] reported that some lignin fractions with a high content of associated carbohydrates had been isolated. The lignin structure and LCC linkages have also been quantitated [38]. Analysis of carbohydrate compositions have shown that xylan is the main polysaccharide type in bamboo; thus, phenyl glycoside linkages consist mostly of the lignin-xylan type but also probably some lignin-glucan types (Tables 1 and 2).

The relative abundances of the main LCC inter-unit linkages and the molar S/G ratios of lignin in LCCs per 100 aromatic units (Ar) are illustrated in Table 5. According to semi-quantitative results, the amounts of phenyl glycoside linkages in $\mathrm{L}_{2}$ and $\mathrm{L}_{24}$ were 6.5 and 12.1 per $100 \mathrm{Ar}$ (monomeric lignin unit), respectively. Evidently, the amount of phenyl glycoside linkages in the $\mathrm{L}_{24}$ preparation was higher than in the $\mathrm{L}_{2}$ preparation. A significant amount of xylose was present in the hemicelluloses of the 24-month-old bamboo (Table 2), indicating that the lignin-xylan type of phenyl glycoside linkage was predominant in the mature bamboo LCC preparation. Zhang et al. [20] have recently studied phenyl glycoside linkages in bamboo LCC and the results match the data obtained in the present study fairly well. Other LCC linkages, such as ether linkages and ester LCC bonds, were also estimated by this methodology and the results are listed in Table 5. 
Table 5. Quantification of LCC linkages (\%, based on $100 \mathrm{Ar}$ ) and average molecular weight of the $\mathrm{L}_{2}$ and $\mathrm{L}_{24}$ preparations.

\begin{tabular}{cccccccc}
\hline \multirow{2}{*}{ Sample } & \multicolumn{3}{c}{ LCC Linkages $^{\text {a }}$} & \multicolumn{4}{c}{ Average Molecular Weight (g/mol) } \\
\cline { 2 - 7 } & Phenyl Glycoside & Benzyl Ether & $\alpha$-Ester & S/G $^{\mathbf{b}}$ & $\boldsymbol{M}_{\boldsymbol{w}}$ & $\boldsymbol{M}_{\boldsymbol{n}}$ & $\boldsymbol{M}_{\boldsymbol{w}} / \boldsymbol{M}_{\boldsymbol{n}}$ \\
\hline $\mathrm{L}_{2}$ & 6.5 & 1.2 & 1.5 & 0.18 & 8650 & 8140 & 1.06 \\
$\mathrm{~L}_{24}$ & 12.1 & 1.9 & 0.5 & 0.87 & 9890 & 9670 & 1.02 \\
\hline \multicolumn{4}{c}{${ }^{\text {a }}$ Per 100 Ar, pooled standard error $( \pm 5 \%) ;{ }^{b} \mathrm{~S} / \mathrm{G}$, syringyl/guaiacyl. }
\end{tabular}

Ether linkages are the primary type of alkali-stable LCC bonds [29]. Freudenberg et al. [19,39] have reported that the benzyl ether LCC bonds were estimated based on the model compound experiments. The cross-signals corresponding to the $\mathrm{CH}-\alpha$ correlations of lignin and the primary $\mathrm{OH}$ groups of carbohydrates are observed in the area of 82.5-80.0/4.7-4.3 ppm (at C-6 of Glc, Gal, and Man, and C-5 of Ara) [40]. As shown in Table 5, the relative amount of benzyl ether LCC bonds in the $\mathrm{L}_{2}$ preparation $(1.2 / 100 \mathrm{Ar})$ was lower than in the $\mathrm{L}_{24}$ preparation $(1.9 / 100 \mathrm{Ar})$, and it was lower than the amount of phenyl glycoside linkages. Eriksson et al. [12] reported that some types of neutral sugar residues in hemicelluloses bind to lignin, probably by benzyl ether bonds. The data shown in Table 2 clearly illustrate that mature bamboo hemicelluloses contain more xylose because the $\mathrm{L}_{24}$ preparation had a higher content of benzyl ether bonds. In addition, C- 6 of glucose is associated with lignin by benzyl ether LCC linkages [32]. Combined with sugar analysis, more glucose existed in $\mathrm{H}_{2}$, and thus the $\mathrm{L}_{2}$ preparation probably contained higher amounts of the lignin-glucan ether bond type.

Ester LCC bonds are known as the primary type of alkali-labile LCC bond [29]. The signals for benzyl ester bonds at 75-77/6.0-6.2 ppm are attributed to the $\mathrm{C}_{\alpha}-\mathrm{H}_{\alpha}$ correlations. The $\mathrm{C}_{\gamma}-\mathrm{H}_{\gamma}$ signals in benzyl ester are observed in the 2D-HSQC spectrum at 65-62/4.5-4.0 ppm. The LCC linkages in bamboo are more sophisticated than in wood as a result of the ferulic acid and $p$-coumaric acid, and this will affect the calculation of the amount of benzyl ester. For this reason, the signal in area $C_{\alpha}$ (located in the left column) was integrated to estimate the amount of benzyl ester LCC bonds [20]. The signals at 72.74/3.37 and 73.89/3.48 ppm in the HSQC spectrum are assigned to $\mathrm{CH}_{2}$ and $\mathrm{CH}_{3}$ in glucuronic acid (GlcA), whereas the intensities of the cross-peak of glucuronic acid for $\mathrm{L}_{24}$ are weaker than that of $L_{2}$ (Figure 2); thus, significant amounts of ester LCC bonds have been discovered in the $\mathrm{L}_{2}$ preparation. Table 5 shows that the relative amounts of benzyl ester LCC bonds in the $\mathrm{L}_{2}$ preparation $(1.5 / 100 \mathrm{Ar})$ were higher than in the $\mathrm{L}_{24}$ preparation $(0.5 / 100 \mathrm{Ar})$. Eriksson et al. [12] have reported that 4-O-methylglucuronic acid is linked to lignin by benzyl ester bonds. Taking the sugar analysis of hemicelluloses into consideration, the changes in the ester linkages are identical to the value of glucuronic acid.

\subsection{Molecular Weight Analysis}

The values of the weight-average $\left(M_{w}\right)$ and number-average $\left(M_{n}\right)$ molecular weights and the polydispersity $\left(M_{w} / M_{n}\right)$ of $\mathrm{L}_{2}$ and $\mathrm{L}_{24}$ were determined by gel permeation chromatography (GPC) and the data are illustrated in Table 5. The weight-average molecular weights $\left(M_{w}\right)$ of $L_{2}$ and $L_{24}$ preparations were determined to be 8650 and $9890 \mathrm{~g} / \mathrm{mol}$, respectively. Clearly, the weight-average molecular weight of the $\mathrm{L}_{24}$ preparation was slightly higher than the $\mathrm{L}_{2}$ preparation. The $\mathrm{L}_{2}$ and $\mathrm{L}_{24}$ preparations exhibited similar polydispersity that was 1.10 and 1.02, respectively. Therefore, all LCC preparations had relatively narrow molecular weight distributions. The relatively low molecular weights of the LCC preparations suggest that the extract process degraded the LCC preparations to a noticeable extent. However, HSQC NMR and FT-IR spectra show that the process did not significantly change the core of the LCC structure. 


\section{Materials and Methods}

\subsection{Preparation of Bamboo Culms Powder}

The bamboo (Neosinocalamus affinis) culms of 2-month-old and 24-month-old bamboo were harvested in Sichuan province, China, in winter. They were labeled as $S_{2}$ and $S_{24}$. The air-dried bamboo culms were cut into chips and were converted into bamboo meal (40-60 mesh particle size) in a micro plant grinding machine. Subsequently, the bamboo meals were extracted with a mixture of toluene/ethanol 2:1 $(v / v)$ in a Soxhlet apparatus for $6 \mathrm{~h}$. The sample of extractive-free meal, after drying over a cabinet oven at $60{ }^{\circ} \mathrm{C}$, was ground in a planetary ball mill (Fritsch, Idar-Oberstein Germany) using a $\mathrm{ZrO}_{2}$ bowl with mixed balls to increase the accessibility of the substrate in subsequent experimental procedures. The 2-month-old ball-milled bamboo powder was darker than the 24-month-old ball-milled bamboo powder. All experiments were performed at least in duplicate.

\subsection{Preparation of LCCS}

LCC preparations were isolated from 2-month-old and 24-month-old bamboo according to the methods of previous works [10,20]. The scheme is summarized in Figure 4, and the detailed procedures are as follows. The ball-milled sample was immersed in $96 \%$ aqueous dioxane $(v / v)$ with a solid to liquid ratio of 1:20 (g/mL) at room temperature for $24 \mathrm{~h}$ under stirring. The procedure was conducted in the dark under a nitrogen atmosphere. Then, the residue was washed with aqueous dioxane, and the extracts and washings were collected. The residue was again extracted under the same conditions for three times. All of the extracts and washings were evaporated under vacuum at $50{ }^{\circ} \mathrm{C}$, and a few drops of water were added to the solid matter and evaporated again. The milled wood lignin (MWL) was obtained. The crude MWL was dissolved in $90 \%$ acetic acid $(v / v)$ and the precipitate that formed was separated by centrifugation and discarded. The solution was added dropwise with stirring to the deionized water. The precipitate that formed on addition of the deionized water was separated from the solution by centrifugation. The solution was concentrated by rotary vacuum evaporation and then freeze-dried to obtain LCC preparations (labeled as $\mathrm{L}_{2}$ and $\mathrm{L}_{24}$ ).

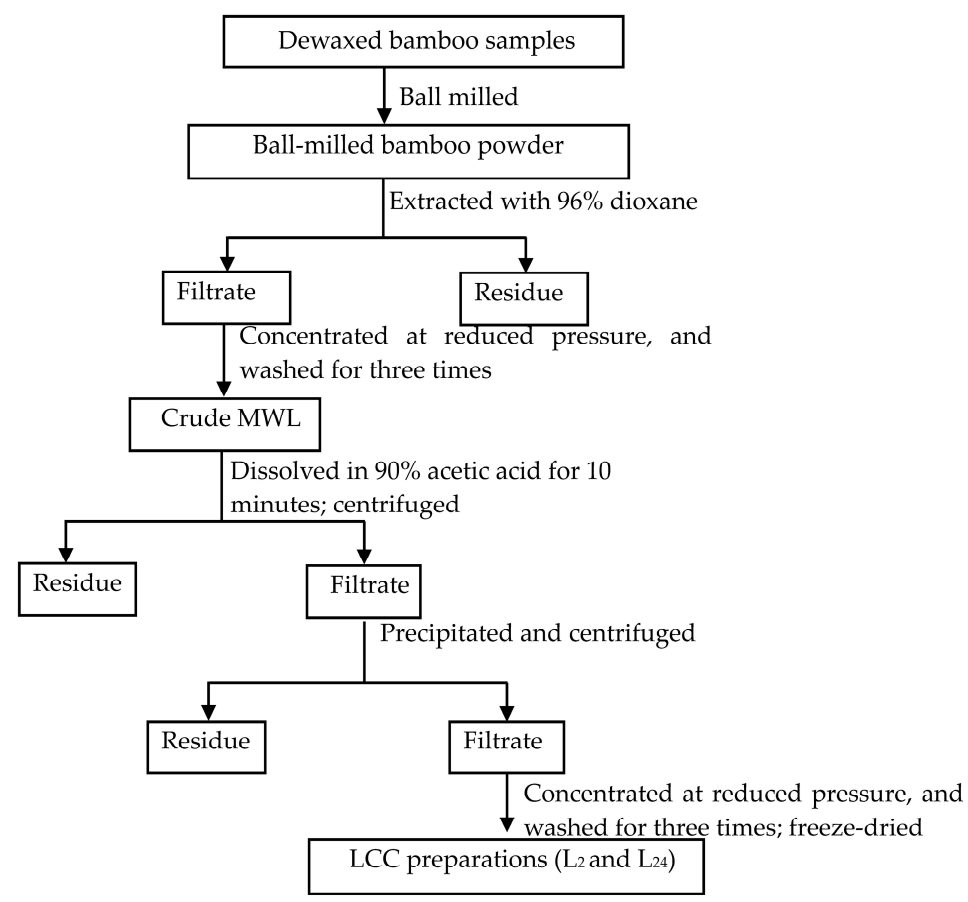

Figure 4. Scheme for LCC preparations $\left(\mathrm{L}_{2}\right.$ and $\left.\mathrm{L}_{24}\right)$ isolated from 2-month-old and 24-month-old bamboo (Neosinocalamus affinis) crude milled wood lignin (MWL). 


\subsection{Preparation of Hemicelluloses}

In order to better understand the structure of LCCs, the hemicelluloses were extracted from the delignification samples. According to the literature [24], the holocellulose was extracted by dimethyl sulfoxide (DMSO) with a solid to liquid ratio of $1: 25(\mathrm{~g} / \mathrm{mL})$ at $80^{\circ} \mathrm{C}$ for $7 \mathrm{~h}$ under stirring. The filtrate was concentrated in a rotary evaporator at reduced pressure and precipitated in three volumes of ethanol under stirring. The precipitate was recovered by centrifugation ( $3500 \mathrm{rpm}, 15 \mathrm{~min}$ ) and freeze-drying; hemicelluloses were obtained (labeled as $\mathrm{H}_{2}$ and $\mathrm{H}_{24}$ ).

\subsection{Analytical Methods}

The chemical compositions of the bamboo culms LCCs were determined according to the standard of National Renewable Energy Laboratory (NREL) [41]. Molecular weights and molecular weight distributions of all LCC preparations were analyzed by gel permeation chromatography (GPC) using a PL-gel $10 \mu \mathrm{m}$ Mixed-B $7.5 \mathrm{~mm}$ i.d. column. GPC analyses were run at least twice [32]. The LCC sample (4 mg) was dissolved in chromatographically pure tetrahydrofuran $(2 \mathrm{~mL})$, filtrated through a $0.22 \mu \mathrm{m}$ organic filter, and then $10 \mu \mathrm{L}$ solution was injected. The column was operated at ambient temperature and eluted with tetrahydrofuran at a flow rate of $1 \mathrm{~mL} / \mathrm{min}$. The hemicellulose fraction (4 6 mg) was hydrolyzed in $1 \mathrm{M}$ sulphuric acid at $105^{\circ} \mathrm{C}$ for $2.5 \mathrm{~h}$. The composition of neutral sugars and uronic acid in the samples was analyzed by high-performance anion exchange chromatography (HPAEC) system (Dionex ISC 3000, Sunnyvale, CA, USA) [42]. All measurements were performed at least in duplicate.

The samples were prepared by grinding $1 \mathrm{mg}$ sample/100 $\mathrm{mg}$ pre-dried $\mathrm{KBr}$. Then they were determined in a FT-IR spectrometer with 64 scans between $4000 \mathrm{~cm}^{-1}$ and $400 \mathrm{~cm}^{-1}$ at $4 \mathrm{~cm}^{-1}$ resolution [43]. 2D-HSQC spectra were recorded by a Bruker NMR spectrometer at $400 \mathrm{MHz}$, using dimethyl sulfoxide- $d_{6}$ (DMSO- $d_{6}$ ) as the solvent. The amounts of LCC preparation linkages were calculated by the mean of parallel samples and the results were expressed as how many linkages per 100 aromatic rings [44]. The formulas are listed as follows:

$$
\begin{gathered}
\text { IC9 units }=0.5 \mathrm{IS} 2,6+\mathrm{IG} 2+0.5 \mathrm{IH} 2,6(\text { grass lignin }) \\
\mathrm{AX}=\mathrm{IX} / \mathrm{IC} 9 \times 100 \%
\end{gathered}
$$

In the formula, all the integration should be in the same contour level. IS2,6, IG2, and IH2,6 represent the integration of S2,6, G2, and H2,6, respectively. AX and IC9 represent the integration of the amount of the main LCC linkages and the aromatic ring, where IX is the integral value of the objective linkages. Table 5 shows the calculation of the amounts of the LCC linkages and the S/G ratios of the LCC preparations.

\section{Conclusions}

Structural characterization of the lignin-carbohydrate complex (LCC) was conducted on 2-month-old and 24-month-old bamboo (Neosinocalamus affinis). It was found that the LCC preparations consisted of glucuronoarabinoxylan and the G-S-H lignin type with $\mathrm{G}>\mathrm{S}>>\mathrm{H}$. The content of the $\mathrm{S}$ units in the LCC preparation from mature bamboo was always higher than from young bamboo. An analysis of the main chemical composition revealed that the content of the acid-soluble lignin in young bamboo LCC is higher than in mature bamboo LCC. The relatively low molecular weight of LCC preparations suggests that this process degraded the LCC to a degree, while 2D-HSQC NMR and FT-IR spectra show that the process did not strongly affect LCC primary structure. An analysis of the sugar composition and the 2D-HSQC NMR show that the content of phenyl glycoside and ether linkages in the $\mathrm{L}_{24}$ preparation was higher than in the $\mathrm{L}_{2}$ preparation, and that the reverse relationship was present for the ester LCC bonds in the $\mathrm{L}_{2}$ and $\mathrm{L}_{24}$ preparations. Lignin-xylan is the main type of LCC linkage in the bamboo LCC. Lignin-lignin linkages in the LCC preparations include $\beta-\beta, \beta-5$, 
and $\beta-1$ carbon-to-carbon as well as $\beta-O-4$ ether linkages, but the $\beta-1$ type was not present in $\mathrm{L}_{2}$. Our studies have provided evidence for differences in LCC structures between the cell walls from young and mature Neosinocalamus affinis bamboo culms.

Acknowledgments: This work was supported by the Fundamental Research Funds for Central Universities (YX2015-07) and the National Natural Science Foundation of China (31470417), the National Excellent Doctoral Dissertations of China Award (201458), and the National Program for Support of Top-Notch Young Professionals.

Author Contributions: Pan-Pan Yue performed the experiments; Ya-Jie $\mathrm{Hu}$, Gen-Que Fu, and Chang-Xia Sun analyzed the data; the paper was written under the direction and supervision of Ming-Fei Li, Feng Peng, and Run-Cang Sun; Pan-Pan Yue was responsible for writing this work.

Conflicts of Interest: The authors declare no conflict of interest.

\section{References}

1. Bridgwater, A.V.; Meier, D.; Radlein, D. An overview of fast pyrolysis of biomass. Org. Geochem. 1999, 30, 1479-1493. [CrossRef]

2. Deutschmann, R.; Dekker, R.F. From plant biomass to bio-based chemicals: Latest developments in xylan research. Biotechnol. Adv. 2012, 30, 1627-1640. [CrossRef] [PubMed]

3. O'Sullivan, A.C. Cellulose: The structure slowly unravels. Cellulose 1997, 4, 173-207. [CrossRef]

4. Scheller, H.V.; Ulvskov, P. Hemicelluloses. Annu. Rev. Plant Biol. 2010, 61, 263-289. [CrossRef] [PubMed]

5. Higuchi, T.; Kawamura, I. Occurrence of p-hydroxyphenylglycerol-beta-aryl ether structure in lignins. Holzforschung 1966, 20, 16.

6. Higuchi, T. Lignin biochemistry: Biosynthesis and biodegradation. Wood Sci. Technol. 1990, 24, 23-63. [CrossRef]

7. Hu, Z.J.; Yeh, T.F.; Chang, H.M.; Matsumoto, Y.J.; Kadla, J.F. Elucidation of the structure of cellulolytic enzyme lignin. Holzforschung 2006, 50, 1040-1397. [CrossRef]

8. Björkman, A. Lignin and lignin-carbohydrate complexes-extraction from wood meal with neutral solvents. Ind. Eng. Chem. 1957, 49, 1395-1398. [CrossRef]

9. Toikka, M.; Sipilä, J.; Teleman, A.; Brunow, G. Lignin-carbohydrate model compounds. Formation of lignin-methyl arabinoside and lignin-methyl galactoside benzyl ethers via quinone methide intermediates. J. Chem. Soc. Perkin Trans. 1998, 22, 3813-3818. [CrossRef]

10. Bjorkman, A. Studies on finely divided wood. Part III. Extraction of lignin-carbohydrate complexes with neutral solvents. Svensk Papperstidn 1957, 60, 243-251.

11. Helm, R.F. Lignin—Polysaccharide Interactions in Woody Plants. In Lignin: Historical, Biolocal, and Merials Perspectives; Glasser, W.G., Northey, R.A., Schultz, T.P., Eds.; ACS Publications: Washington, DC, USA, 1999; Volume 742, pp. 161-171.

12. Eriksson, Ö.; Goring, D.A.I.; Lindgren, B.O. Structural studies on the chemical bonds between lignins and carbohydrates in spruce wood. Wood Sci. Technol. 1980, 14, 267-279. [CrossRef]

13. Imamura, T.; Watanabe, T.; Kuwahara, M.; Koshijima, T. Ester linkages between lignin and glucuronic acid in lignin-carbohydrate complexes from Fagus crenata. Phytochemistry 1994, 37, 1165-1173. [CrossRef]

14. Karlsson, O.; Westermark, U. Evidence for chemical bonds between lignin and cellulose in kraft pulps. J. Pulp Pap. Sci. 1996, 22, J397-J401.

15. Yaku, F.; Tsuji, S.; Koshijima, T. Lignin carbohydrate complex. Pt. III. Formation of micells in the aqueous solution of acidic lignin carbohydrate complex. Holzforschung 1979, 33, 54-59. [CrossRef]

16. Aimi, H.; Matsumoto, Y.; Meshitsuka, G. Structure of small lignin fragments retained in water-soluble polysaccharides extracted from birch MWL isolation residue. J. Wood Sci. 2005, 51, 303-308. [CrossRef]

17. Guerra, A.; Filpponen, I.; Lucia, L.A.; Argyropoulos, D.S. Comparative evaluation of three lignin isolation protocols for various wood species. J. Agric. Food Chem. 2006, 54, 9696-9705. [CrossRef] [PubMed]

18. Azuma, J.I.; Takahashi, N.; Koshijima, T. Isolation and characterisation of lignin-carbohydrate complexes from the milled-wood lignin fraction of Pinus densiflora sieb. et zucc. Carbohydr. Res. 1981, 93, 91-104. [CrossRef] 
19. Freudenberg, K.; Grion, G. Beitrag zum Bildungsmechanismus des Lignins und der Lignin-Kohlenhydrat-Bindung. Eur. J. Inorg. Chem. 1959, 92, 1355-1363. [CrossRef]

20. Zhang, B.; Fu, G.Q.; Niu, Y.S.; Peng, F.; Yao, C.L.; Sun, R.C. Variations of lignin-lignin and lignin-carbohydrate linkages from young Neosinocalamus affinis bamboo culms. RSC Adv. 2016, 6, 15478-15484. [CrossRef]

21. Yin, H.S.; Liu, H.M.; Liu, Y.L. Structural Characterization of lignin in fruits and stalks of Chinese Quince. Molecules 2017, 22, 890. [CrossRef]

22. Yoshida, S.; Kuno, A.; Saito, N.; Aoyama, M.; Kusakabe, I. Structure of xylan from culms of bamboo grass (Sasa senanensis Rehd.). J. Wood Sci. 1998, 44, 457-462. [CrossRef]

23. Peng, P.; She, D. Isolation, structural characterization, and potential applications of hemicelluloses from bamboo: A review. Carbohydr. Polym. 2014, 112, 701-720. [CrossRef] [PubMed]

24. Zhang, B.; Guan, Y.; Bian, J.; Peng, F.; Ren, J.L.; Yao, C.L.; Sun, R.C. Structure of hemicelluloses upon maturation of bamboo (Neosinocalamus affinis) culms. Cellul. Chem. Technol. 2016, 50, 189-198.

25. Atsushi, K.; Azuma, J.; Koshijima, T. Lignin-carbohydrate complexes and phenolic acids in bagasse. Holzforschung 1984, 38, 141-149. [CrossRef]

26. Bai, Y.Y.; Xiao, L.P.; Shi, Z.J.; Sun, R.C. Structural variation of bamboo lignin before and after ethanol organosolv pretreatment. Int. J. Mol. Sci. 2013, 14, 21394-21413. [CrossRef] [PubMed]

27. Kang, S.M.; Xiao, L.P.; Meng, L.Y.; Zhang, X.M.; Sun, R.C. Isolation and structural characterization of lignin from cotton stalk treated in an ammonia hydrothermal system. Int. J. Mol. Sci. 2012, 13, 15209-15226. [CrossRef] [PubMed]

28. Balakshin, M.; Capanema, E.; Gracz, H.; Chang, H.M.; Jameel, H. Quantification of lignin-carbohydrate linkages with high-resolution NMR spectroscopy. Planta 2011, 233, 1097-1110. [CrossRef] [PubMed]

29. Balakshin, M.Y.; Capanema, E.A.; Chang, H. MWL fraction with a high concentration of lignin-carbohydrate linkages: Isolation and 2D NMR spectroscopic analysis. Holzforschung 2007, 61, 1-7. [CrossRef]

30. Wen, J.L.; Sun, Z.; Sun, Y.C.; Sun, S.N.; Xu, F.; Sun, R.C. Structural characterization of alkali-extractable lignin fractions from bamboo. J. Biobased Mater. Bioenergy 2010, 4, 408-425. [CrossRef]

31. You, T.T.; Zhang, L.M.; Zhou, S.K.; Xu, F. Structural elucidation of lignin-carbohydrate complex (LCC) preparations and lignin from Arundo donax Linn. Ind. Crop. Prod. 2015, 71, 65-74. [CrossRef]

32. Wen, J.L.; Xue, B.L.; Xu, F.; Sun, R.C.; Pinkert, A. Unmasking the structural features and property of lignin from bamboo. Ind. Crop. Prod. 2013, 42, 332-343. [CrossRef]

33. Yuan, T.Q.; Sun, S.N.; Xu, F.; Sun, R.C. Characterization of lignin structures and lignin-carbohydrate complex (LCC) linkages by quantitative ${ }^{13} \mathrm{C}$ and 2D HSQC NMR spectroscopy. J. Agric. Food Chem. 2011, 59, 10604. [CrossRef] [PubMed]

34. Zhou, J.M.; Ibrahim, R.K. Tricin-A potential multifunctional nutraceutical. Phytochem. Rev. 2010, 9, 413-424. [CrossRef]

35. Koshijima, T.; Watanabe, T. Association Between Lignin and Carbohydrates in Wood and Other Plant Tissues; Springer: Heidelberg, Gernmany, 2003; pp. 91-126.

36. Adler, E. Lignin chemistry-Past, present and future. Wood Sci. Technol. 1977, 11, 169-218. [CrossRef]

37. Terashima, N.; Ralph, S.A.; Landucci, L.L. New facile syntheses of monolignol glucosides; p-glucocoumaryl alcohol, coniferin and syringin. Holzforschung 1996, 50, 151-155.

38. Zhang, L.; Gellerstedt, G. Quantitative 2D HSQC NMR determination of polymer structures by selecting suitable internal standard references. Magn. Reson. Chem. 2007, 45, 37-45. [CrossRef] [PubMed]

39. Freudenberg, K.; Harkin, J.M. Modelle für die Bindung des Lignins an die Kohlenhydrate. Eur. J. Inorg. Chem. 1960, 93, 2814-2819. [CrossRef]

40. Tokimatsu, T.; Umezawa, T.; Shimada, M. Synthesis of four diastereomeric lignin carbohydrate complexes (LCC) model compounds composed of a $\beta$-O-4 lignin model linked to methyl $\beta$-D-glucoside. Holzforschung 1996, 50, 156-160. [CrossRef]

41. Sluiter, A.; Hames, B.; Ruiz, R.; Scarlata, C.; Sluiter, J.; Templeton, D.; Crocker, D. Determination of Structural Carbohydrates and Lignin in Biomass; Technical Report for Laboratory Analytical Procedure (LAP), NREL: Golden, CO, USA, 2008.

42. Peng, F.; Ren, J.L.; Xu, F.; Bian, J.; Peng, P.; Sun, R.C. Fractionation of alkali-solubilized hemicelluloses from delignified Populus gansuensis: Structure and properties. J. Agric. Food Chem. 2010, 58, 5743-5750. [CrossRef] [PubMed] 
43. Yuan, T.Q.; Xu, F.; He, J.; Sun, R.C.; Liu, S.J.; Zhang, Z.S.; Scott, G. Structural and physico-chemical characterization of hemicelluloses from ultrasound-assisted extractions of partially delignified fast-growing poplar wood through organic solvent and alkaline solutions. Biotechnol. Adv. 2010, 28, 583-593. [CrossRef] [PubMed]

44. Wen, J.L.; Sun, S.L.; Xue, B.L.; Sun, R.C. Recent Advances in Characterization of lignin polymer by solution-state nuclear magnetic resonance (NMR) methodology. Materials 2013, 6, 359-391. [CrossRef] [PubMed]

(c) (c) 2017 by the authors. Licensee MDPI, Basel, Switzerland. This article is an open access article distributed under the terms and conditions of the Creative Commons Attribution (CC BY) license (http:/ / creativecommons.org/licenses/by/4.0/). 